\title{
Analisis Bifurkasi Hopf Pada Sistem Keuangan dengan Kontrol Input
}

\author{
Anggita Dwi Saputri, Hariyanto, dan Mohammad Setijo Winarko \\ Departemen Matematika, Fakultas MKSD, Institut Teknologi Sepuluh Nopember (ITS) \\ e-mail: hariyanto@matematika.its.ac.id
}

\begin{abstract}
Abstrak-Sistem Keuangan mempunyai peran penting dalam ekonomi dimana stabilitas sistem keuangan mempengaruhi stabilitas ekonomi. Ketidakstabilan sistem keuangan dapat mengakibatkan timbulnya masalah yang sangat berdampak pada kegiatan ekonomi, seperti krisis keuangan. Penelitian ini menganalisis perilaku dinamis model matematika sistem keuangan. Oleh karena itu, diperlukan adanya kajian terhadap dinamika sistem keuangan dengan menggunakan model matematika untuk mengetahui sistem keuangan yang berkaitan dengan kestabilan sistem. Analisis dinamika model matematika sistem keuangan pada penelitian ini meliputi mencari titik tetap, menentukan kestabilitan titik tetap menggunakan kriteria Routh-Hurwitz, dan analisis bifurkasi Hopf. Bifurkasi Hopf terjadi pada titik tetap $E_{0}$. Eksistensi bifurkasi Hopf bergantung pada biaya per investasi di pasar komersial sebagai parameter bifurkasi. Hasil analisis menunjukkan adanya bifurkasi Hopf yang mengelilingi titik tetap positif. Untuk mendukung hasil analisis dilakukan simulasi numerik dengan menggunakan Runge-Kutta orde empat.
\end{abstract}

Kata Kunci-Bifurkasi Hopf, Metode Runge-Kutta, Sistem Keuangan, Stabilitas.

\section{PENDAHULUAN}

$\mathrm{S}^{\mathrm{s}}$ ISTEM keuangan merupakan satu kesatuan jaringan yang menggambarkan interaksi lembaga-lembaga keuangan dan pasar. Interaksi yang terjadi dalam sistem keuangan sangat kompleks, berkaitan dengan mobilitas dana, baik dalam kegiatan investasi, penyediaan keuangan, maupun pembiayaan kegiatan komersial. Lembaga keuangan berperan penting terutama sebagai penengah antara lembagalembaga yang menyediakan dana dan lembaga-lembaga yang membutuhkan dana, sedangkan pasar berperan penting dalam memfasilitasi pengelolaan dana dan transformasi risiko[1].

Kestabilan sistem keuangan berdampak besar terhadap jalannya kegiatan ekonomi. Sistem keuangan dikatakan stabil ketika mekanisme ekonomi dalam penetapan harga instrumen keuangan, alokasi dana, dan pengelolaan dana berfungsi secara baik dan mendukung kegiatan ekonomi. Mekanisme ekonomi dalam penetapan harga instrumen keuangan, alokasi dana, dan pengelolaan dana tersebut sangat berkaitan dengan fenomena-fenomena perubahan suku bunga, perubahan tingkat permintaan investasi, dan perubahan indeks harga instrumen keuangan. Ketiga fenomena tersebut saling berhubungan satu sama lain dan tidak terlepas dari pengaruh total tabungan nasional, biaya investasi, dan elastisitas permintaan. Jika terdapat ketidaksesuaian antara faktorfaktor yang saling berpengaruh tersebut di dalam sistem keuangan, maka permasalahan yang ditimbulkan sangat kompleks dan dapat berujung pada krisis keuangan[1].

Metode pengendalian yang efektif dan cepat sangat penting bagi pemerintah ketika beberapa kasus yang rumit muncul. Model sistem keuangan tiga dimensi yang menggambarkan variasi waktu penyesuaian negara telah dipublikasikan antara lain mencakup tingkat suku bunga, indeks harga, dan permintaan investasi. Kemudian, sistem keuangan tiga dimensi yang rumit serta risiko dari analisis sistem dinamis yang dibangun untuk mengatur pasar keuangan telah terbukti dapat dikendalikan secara efektif [2][3]. Demikian pula pada [4]dengan menggunakan metode delayed feedback control (DFC) dan membuktikan bahwa sistem keuangan yang rumit dapat distabilkan pada berbagai orbit periodik.

Pada studi ini, penulis menganalisis kestabilan dengan menggunakan Kriteria Routh-Hurwitz dan Bifurkasi Hopf pada model matematika sistem keuangan dengan empat variable. Serta memberikan penyelesaian numerik dengan menggunakan metode numerik Runge-Kutta yang disajikan dalam bentuk simulasi sehingga hasil simulasi merepresentasikan hasil analisis dari model tersebut.

\section{METODE PENELITIAN}

\section{A. Studi Literatur}

Tahap ini merupakan tahap untuk melakukan identifikasi permasalahan, yaitu mencari referensi yang menunjang penelitian.Referensi bisa berupa tugas akhir, jurnal, buku, maupun artikel terkait.

\section{B. Tahap Mengkaji Model Matematika Sistem Keuangan}

Pada tahap ini, dilakukan kajian terhadap model sistem keuangan agar representasi dinamika sistem keuangan dalam kehidupan nyata dapat dipahami melalui model matematika sistem keuangan.

\section{Tahap Mencari Titik Tetap dan Translasi Titik Tetap}

Pada tahap ini, dicari titik tetap dari model matematika sistem keuangan, yaitu titik yang diperoleh ketika sistem dalam keadaan stasioner atau ketika tidak terjadi perubahan terhadap waktu. Dilakukan translasi titik tetap sistem ke titik asal untuk mempermudah analisis kestabilan dan eksistensi bifurkasi Hopf pada model sistem keuangan.

\section{Tahap Linearisasi Sistem Nonlinear}

Pada tahap ini, dilakukan pelinearan terhadap sistem model sistem keuangan karena model sistem keuangan adalah model sistem dinamik nonlinear.

\section{E. Tahap Kriteria Kestabilan Routh-Hurwitz}

Pada tahap ini, diselidiki kestabilan dari titik tetap dengan menggunakan kriteria Routh-Hurwitz. 


\section{F. Tahap Menyelediki Eksistensi Bifurkasi Hopf}

Pada tahap ini, berdasarkan titik tetap yang dicari pada tahap sebelumnya, selanjutnya pada tahap ini dilakukan analisis mengenai eksistensi bifurkasi Hopf.

\section{G. Tahap Simulasi Numerik}

Pada tahap ini, dilakukan analisis hubungan antara bilangan reproduksi dasar dan stabilitas titik kesetimbangan dengan metode numerik Runge Kutta orde 4, menggunakan software MATLAB2016b.

\section{H. Kesimpulan dan Saran}

Pada tahap terakhir ini, dilakukan penarikan simpulan dari hasil pembahasan sebelumnya.Selanjutnya, diberikan saran untuk perbaikan pada penelitian berikutnya.

\section{ANALISIS DAN PEMBAHASAN}

\section{A. Model Sistem Keuangan}

Model umum sistem keuangan secara sederhana dapat ditulis dengan empat variabel, yaitu suku bunga $x$, tingkat permintaan investasi $y$, indeks harga instrumen keuangan $z$ dan $u$ control input dan intervensi ekonomi untuk menyeimbangkan lingkungan ekonomi berikut ini :

$\left\{\begin{array}{l}\dot{x}=z+(y-a) x \\ \dot{y}=1-b y-x^{2} \\ \dot{z}=-x-c z+u \\ \dot{u}=-d x y-k u-m z\end{array}\right.$

dengan $a \geq 0$ adalah total tabungan di bank, $b \geq 0$ adalah biaya per investasi, $c \geq 0$ adalah elastisitas permintaan, $\mathrm{d}, \mathrm{k}$, dan $m$ adalah amplitudo yang sesuai [5].

\section{B. Titik Tetap Sistem dan Translasi Titik Tetap}

Titik tetap $E\left(x_{0}, y_{0}, z_{0}, u_{0}\right)$ adalah titik yang diperoleh ketika sistem keuangan berada pada keadaan stasioner [6]. Titik tetap dari system (1) diperoleh ketika laju perubahan suku bunga, laju perubahan tingkat permintaan investasi, laju perubahan indeks harga instrumen dan laju perubahan kontrol input sama dengan nol, yaitu

$\left\{\begin{array}{c}z+(y-a) x=0 \\ 1-b y-x^{2}=0 \\ -x-c z+u=0 \\ -d x y-k u-m z=0\end{array}\right.$

untuk $y_{0}=\frac{1}{b}$ diperoleh satu titik tetap $E_{0}\left(0, \frac{1}{b}, 0,0\right)$.

Untuk $y_{0}=\frac{k+a c k+a m}{d-c k-m}$ dengan syarat $d-c k-m \neq 0$ dan dapat kita misalkan $\Gamma_{1}=d-c k-m$ dan $\Gamma_{2}=k+a c k+$ am dengan $0<\Gamma_{1}<b \Gamma_{2}$ makadidapat titik tetap $E_{1,2}\left( \pm x_{0}, y_{0}, \mp z_{0}, \mp u_{0}\right)$ dimana

$$
\begin{gathered}
x_{0}=\frac{\Gamma_{1}-b \Gamma_{2}}{\Gamma_{1}} \\
y_{0}=\frac{\Gamma_{2}}{\Gamma_{1}} \\
z_{0}=(a d+k) \frac{\Gamma_{1}-b \Gamma_{2}}{\Gamma_{1}^{\frac{3}{2}}} \\
u_{0}=(d+a c d-m) \frac{\Gamma_{1}-b \Gamma_{2}}{\Gamma_{1}^{\frac{3}{2}}}
\end{gathered}
$$

\section{Translasi Titik Tetap}

Sistem (1) ditranslasi terlebih dahulu sehingga titik tetap $E_{0}\left(0, \frac{1}{b}, 0,0\right)$ bergeser menjadi $E_{0}{ }^{*}(0,0,0,0)$. Setelah ditransformasi, sistem (1) menjadi :

$$
\left\{\begin{array}{c}
\dot{X}=\left(\frac{1}{b}-a\right) X+Z+X Y \\
\dot{Y}=-b Y-X^{2} \\
\dot{Z}=-X-c Z+U \\
\dot{U}=-d X\left(Y+\frac{1}{b}\right)-k U-m Z
\end{array}\right.
$$

\section{Linearisasi Sistem [6]}

Sistem (1) merupakan system nonlinear. Oleh karena itu system harus dilinearkan terlebih dahulu di sekitar titik tetap $E_{*}\left(x_{*}, y_{*}, z_{*}, u_{*}\right)$. Dimana dapat kita ketahui $E_{*}$ adalah kita misalkan titik tetap dimana didalamnya ada $E_{0}$ dan $E_{1,2}$. Sehingga diperoleh Jacobian sistem di sekitar titik tetap

$$
J=\left[\begin{array}{cccc}
\left(y_{*}-a\right) & x_{*} & 1 & 0 \\
-2 x_{*} & -b & 0 & 0 \\
-1 & 0 & -c & 1 \\
-d y_{*} & -d x_{*} & -m & -k
\end{array}\right]
$$

\section{Kriteria Kestabilan Routh-Hurwitz}

Diperoleh akar akar karakteristik pada persamaan dengan titik tetap $\left(x_{*}, y_{*}, z_{*}, u_{*}\right)$ adalah

$\lambda^{4}+\left(a+b+c+k-y_{*}\right) \lambda^{3}+(1+a b+a c+b c+a k+$ $\left.b k+c k+m+2 x_{*}^{2}-b y_{*}\right) \lambda^{2}+(b+a b c+k+a b k+$ $a c k+b c k+a m+b m+2 c x_{*}^{2}-b c y_{*}+d y_{*}-b k y_{*}-$ $\left.c k y_{*}-m y_{*}\right) \lambda+b k+a b c k+a b m-2 d x_{*}^{2}+2 c k x_{*}^{2}+$

$2 m x_{*}^{2}+b d y_{*}-b c k y_{*}-b m y_{*}=0$

Menggunakan kriteria stabilitas Routh-Hurwitz dalam menganalisis kestabilan pada titik ini seperti yang telah dituliskan pada [6]. maka persamaan karakteristik sistem menjadi:

$h_{0} s^{4}+h_{1} s^{3}+h_{2} s^{2}+h_{3} s+h_{4}=0$

Dengan nilai

$h_{0}=1$,

$h_{1}=a+b+c+k-y_{*}$,

$h_{2}=1+a b+a c+b c+a k+b k+c k+m+2 x_{*}^{2}-b y_{*}$, $h_{3}=b+a b c+k+a b k+a c k+b c k+a m+b m+$ $2 c x_{*}^{2}-b c y_{*}+d y_{*}-b k y_{*}-c k y_{*}-m y_{*}, h_{4}=b k+$ $a b c k+a b m-2 d x_{*}^{2}+2 c k x_{*}^{2}+2 m x_{*}^{2}+b d y_{*}-b c k y_{*}-$ bmy

Berdasarkan [6] agar nilai-nilai karakteristik pada persamaan (5) bernilai negatif maka harus berlaku $h_{4}>0$ dengan

$\left\{\begin{array}{c}h_{1}, h_{2}, h_{3}, h_{4}>0 \\ h_{1} h_{2}-h_{3}>0 \\ h_{1} h_{2} h_{3}-h_{3}^{2}-h_{1}^{2} h_{4}>0\end{array}\right.$

dengan mengambil nilai $h_{1}, h_{2}, h_{3}, h_{4}>0, h_{1} h_{2}-h_{3}>0$ dan $h_{1} h_{2} h_{3}-h_{3}^{2}-h_{1}^{2} h_{4}>0$ maka model sistem keuangan tersebut pada titik tetap $\left(x_{*}, y_{*}, z_{*}, u_{*}\right)$ akan bersifat stabil. Namun jika sebaliknya diambil kondisi bahwa $h_{1}<0$ maka sistem akan berada pada kondisi tak stabil.

\section{E. Analisis Bifurkasi Hopf}

Telah dijelaskan sebelumnya bahwa Persamaan 5 akan bersifat stabil jika berlaku $h_{1}, h_{2}, h_{3}, h_{4}>0, h_{1} h_{2}-h_{3}>0$, dan $h_{1} h_{2} h_{3}-h_{3}^{2}-h_{1}^{2} h_{4}>0$. Karena pada titik ini berlaku polinomial yaitu

$h_{0} s^{4}+h_{1} s^{3}+h_{2} s^{2}+h_{3} s+h_{4}=0$ 
Maka berdasarkan teorema 4 bifurkasi Hopf pada titik tetap tersebut terjadi jika $h_{0}>0, h_{1}>0, h_{1} h_{2}-h_{3}>0$ dan $h_{1} h_{2} h_{3}-h_{3}^{2}-h_{1}^{2} h_{4}=0$ berlaku sedemikian hingga

$$
\frac{d}{d b}\left(h_{1} h_{2} h_{3}-h_{3}^{2}-h_{1}^{2} h_{4}\right) \neq 0
$$

Sesuai pada subbab sebelumnya yaitu tentang kriteria kestabilan Routh-Hurwitz dalam hal ini akan diambil $h_{1} \geq 0$, $h_{2} \geq 0$, maka jelas bahwa $h_{1} h_{2} h_{3}=h_{3}^{2}+h_{1}^{2} h_{4}$ agar syarat awal bifurkasi Hopf terjadi dapat dipenuhi dimana $h_{1} h_{2} h_{3} \neq$ $h_{3}^{2}+h_{1}^{2} h_{4}$ untuk $h_{1}<0$ dan $h_{2}<0$.

Untuk mendapatkan turunan dari persamaan diatas maka dapat diperoleh nilai nilai sebagai berikut :

$\frac{d}{d b} h_{1}=1$

$\frac{d}{d b} h_{2}=a+c+k-y_{*}$

$\frac{d}{d b} h_{3}=1+a c+a k+c k+m+\left(-c y_{*}\right)-k y_{*}$

$\frac{d}{d b} h_{4}=k+a c k+a m+c k+m+d y_{*}-c k y_{*}-m y_{*}$

Dalam hal ini dapat berlaku

$\frac{d}{d b}\left(h_{1} h_{2} h_{3}-h_{3}^{2}-h_{1}^{2} h_{4}\right)=\left(h_{2} h_{3}-2 h_{1} h_{4}\right) \frac{d}{d b} h_{1}+$

$h_{1} h_{3} \frac{d}{d b} h_{2}+\left(h_{1} h_{2}-2 h_{3}\right) \frac{d}{d b} h_{3}-h_{1}^{2} \frac{d}{d b} h_{4}$

substitusikan persamaan (8) sampai (11) kedalam persamaan (12) sehingga dapat diperoleh

$\frac{d}{d b}\left(h_{1} h_{2} h_{3}-h_{3}^{2}-h_{1}^{2} h_{4}\right)=\left(h_{2} h_{3}-2 h_{1} h_{4}\right)+h_{1} h_{3}(a+$

$\left.c+k-y_{*}\right)+\left(h_{1} h_{2}-2 h_{3}\right)(1+a c+a k+c k+m+$

$\left.\left(-c y_{*}\right)-k y_{*}\right)-h_{1}^{2}\left(k+a c k+a m+c k+m+d y_{*}-\right.$

$\left.c k y_{*}-m y_{*}\right)$

Berdasarkan persamaan (13) maka jelas bahwa

$$
\begin{aligned}
& \frac{d}{d b}\left(h_{1} h_{2} h_{3}-h_{3}^{2}-h_{1}^{2} h_{4}\right)=\left(h_{2} h_{3}-2 h_{1} h_{4}\right) \frac{d}{d b} h_{1}+ \\
& h_{1} h_{3} \frac{d}{d b} h_{2}+\left(h_{1} h_{2}-2 h_{3}\right) \frac{d}{d b} h_{3}-h_{1}^{2} \frac{d}{d b} h_{4} \neq 0
\end{aligned}
$$

Jadi dapat disimpulkan bahwa pada titik tetap $E_{*}\left(x_{*}, y_{*}, z_{*}, u_{*}\right)$ terdapat parameter $b$ dimana dengan sedikit pergeseran nilai pada $b$ dapat menyebabkan perubahan kestabilan pada sistem. Nilai kritis dari parameter b dimulai ketika kondisi $h_{1} h_{2} h_{3}-h_{3}^{2}-h_{1}^{2} h_{4}=0$. Sehingga benar bahwa pada titik tetap ini memiliki kemungkinan akan adanya bifurkasi Hopf.

Catatan : demi penyerdehanaan sistem perilaku dinamis pada sistem (3.1) diberikan nilai-nilai parameter tetap seperti pada [11] dengan $a=0.9, c=1.5, d=0.2$, dan $k=0.05$.

1. Ketika $m=0.005$, persamaan (1) mempunyai tiga titik setimbang untuk $E_{0}$ dan $E_{1,2}$ :

a. $E_{0}\left(0, \frac{1}{b}, 0,0\right)$

$E_{0}$ stabil asimtotik saat $b>0.7068$ karena syaratsyarat terpenuhi seperti yang sudah dijelaskan pada kriteria kestabilan Routh-Hurwitz.

b. $E_{1,2}\left( \pm x_{0}, y_{0}, \mp z_{0}, \mp u_{0}\right)$

$E_{1,2}$ tidak stabil untuk $b \in \mathbb{R}^{+}$.

Pada syarat stabil adalah ketika $h_{1} h_{2}-h_{3}>0$ namun dapat kita hitung dengan memasukkan nilai-nilai parameter syarat tidak terpenuhi karena $h_{1} h_{2}-h_{3}<$ 0 .

2. Ketika $b=0.2$, persamaan (1) mempunyai tiga titik setimbang untuk $E_{0}$ dan $E_{1,2}$ :

a. $E_{0}\left(0, \frac{1}{b}, 0,0\right)$

sistem tidak stabil untuk $m \in \mathbb{R}^{+}$karena $h_{1}<0$.

\section{b. $E_{1,2}\left( \pm x_{0}, y_{0}, \mp z_{0}, \mp u_{0}\right)$}

$E_{1,2}$ stabil asimtotik saat $m>0.5139$ karena syaratsyarat terpenuhi seperti yang sudah dijelaskan pada kriteria kestabilan Routh-Hurwitz.

Dengan ini dapat diketahui bahwa sistem akan bersifat stabil asimtotik pada saat titik tetap $E_{0}$ dengan syarat nilai dari parameter $b>0.7068$ dan $m=0.005$. Saat titik tetap $E_{1,2}$ akan bersifat stabil asimtotik dengan syarat nilai parameter dari $m>0.5139$ dan $b=0.2$. Dengan memasukkan nilai parameter seperti pada [7] . misalkan $=$ $0.9, c=1.5, d=0.2, k=0.05, b=b_{0}=0.7068$ dan $m=$ 0.005 menggunakan perhitungan numerik diperoleh nilai eigen

1. Pada titik tetap $E_{0}\left(0, \frac{1}{b}, 0,0\right)=E_{0}\left(0, \frac{1}{0.7068}, 0,0\right)$

$$
\begin{aligned}
& \lambda_{1}=-0.7068 \\
& \lambda_{2,3}= \pm 0.5309 i \\
& \lambda_{4}=-1.0351
\end{aligned}
$$

2. Pada titik tetap $E_{1,2}\left( \pm x_{0}, y_{0}, \mp z_{0}, \mp u_{0}\right)$

$$
\begin{aligned}
& \lambda_{1}=0.0557 \\
& \lambda_{2,3}=-1.3722 \pm 2.5857 i \\
& \lambda_{4}=-1.4849
\end{aligned}
$$

Dari perhitungan numerik diatas, diketahui bahwa bifurkasi Hopf terjadi pada titik tetap $E_{0}$ karena terdapat nilai eigen yang mempunyai sepasang bilangan imajiner dengan nilai eigen lainnya bernilai negatif. Selanjutnya akan diselidiki eksistensi bifurkasi Hopf menggunakan simulasi numerik.

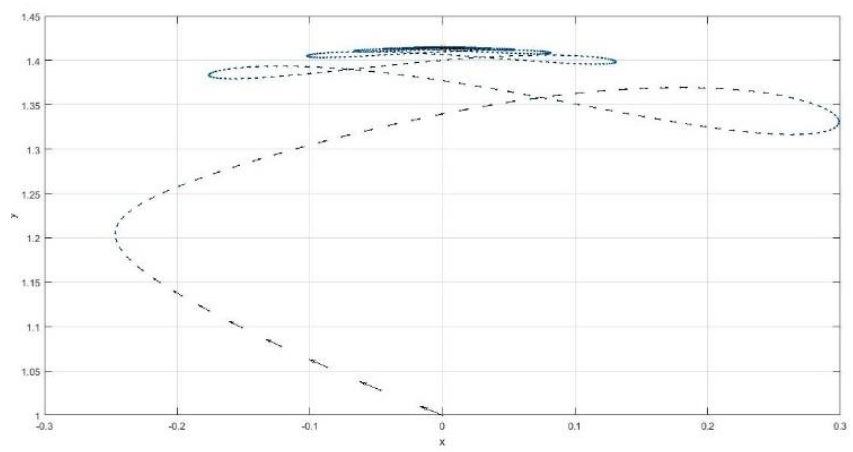

Gambar 1. Trayektori orbit periodik 2D $(x, y)$

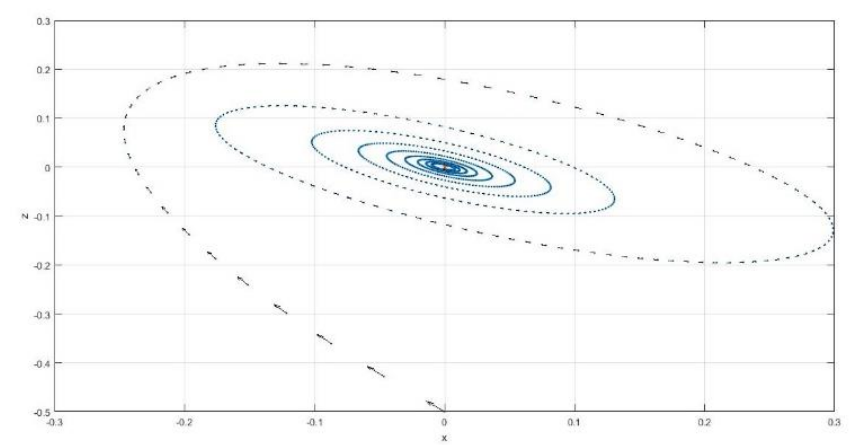

Gambar 2. Trayektori orbit periodik 2D(x,z).

Berdasarkan hasil simulasi pada Gambar 1 sampai dengan Gambar 7, terlihat adanya orbit periodik dengan arah menuju ke limit cycle pada nilai $b=0.7068$, sehingga dapat disimpulkan bifurkasi Hopf adalah bifurkasi Hopf Superkritikal. 


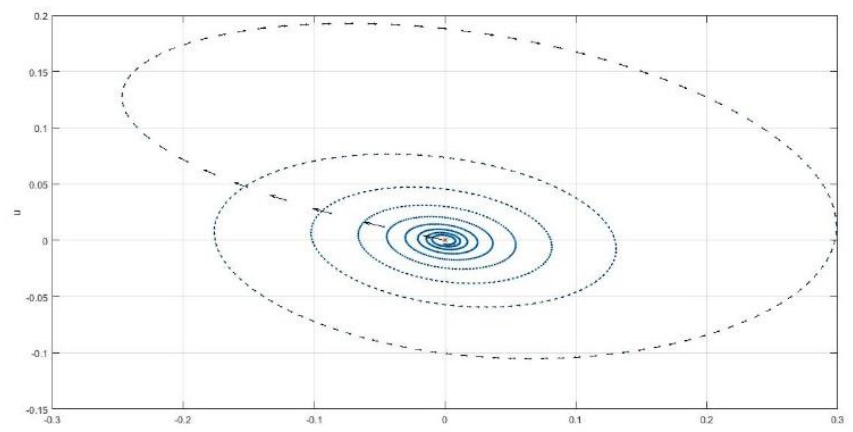

Gambar 3. Trayektori orbit periodik 2D(x,u)

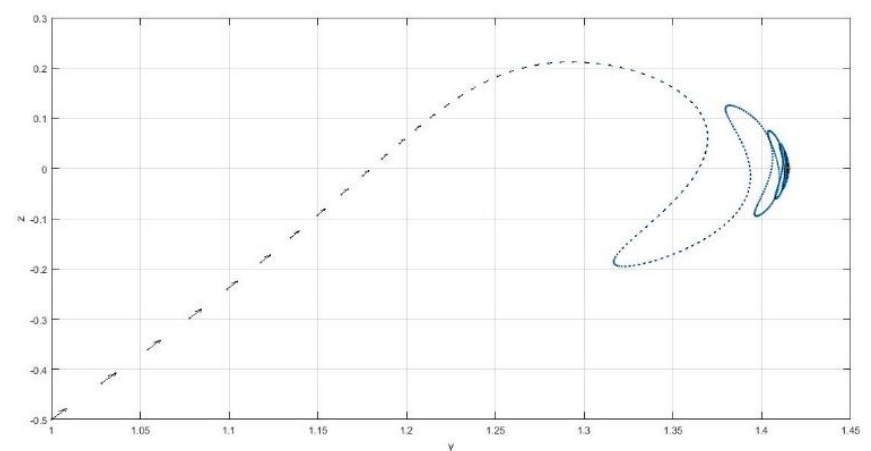

Gambar 4. Trayektori orbit periodik 2D(y,z)

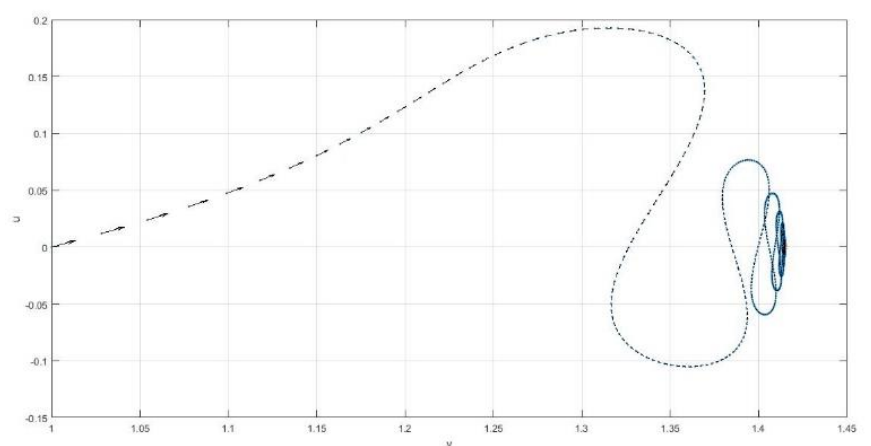

Gambar 5. Trayektori orbit periodik 2D $(y, u)$

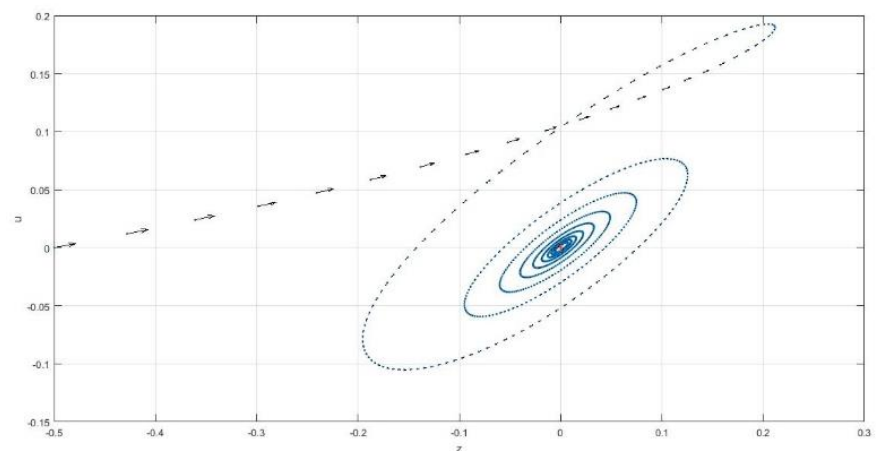

Gambar 6. Trayektori orbit periodik $2 \mathrm{D}(z, u)$

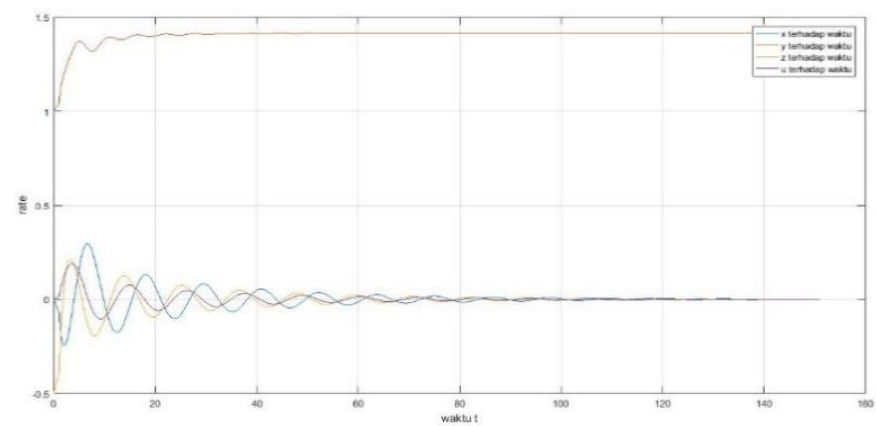

Gambar 7. Grafik kestabilan (x,y,z,u) terhadap fungsi $\mathrm{t}($ waktu) pada $b=$ 0.7068

\section{F. Simulasi Numerik}

Dibahas bagaimana cara untuk memperoleh solusi numerik dari model sistem keuangan dan simulasi numeriknya, serta interpretasi dari hasil analisis yang sudah dilakukan. Penyelesaian numerik dicari dengan menggunakan metode numerik Runge-Kutta orde-4. Metode ini mempunyai suatu galat pemotongan $h^{4}$, dengan $h$ merupakan langkah waktu. Perhatikan kembali sistem (1). Misalkan

$$
\begin{aligned}
& f_{1}(t, x, y, z, u)=\dot{x}=z+(y-a) x \\
& f_{2}(t, x, y, z, u)=\dot{y}=1-b y-x^{2} \\
& f_{3}(t, x, y, z, u)=\dot{z}=-x-c z+u
\end{aligned}
$$

$f_{4}(t, x, y, z, u)=\dot{u}=-d x y-k u-m z$

dan misalkan nilai awal untuk (14) adalah

$$
\begin{aligned}
& x\left(t_{0}\right)=x_{0} \\
& y\left(t_{0}\right)=y_{0} \\
& z\left(t_{0}\right)=z_{0} \\
& u\left(t_{0}\right)=u_{0}
\end{aligned}
$$

maka diperoleh integrasi numerik dengan menggunakan metode numerik Runge-Kutta orde-4 sebagai berikut :

$$
\begin{aligned}
& x_{j+1}=x_{j}+\frac{1}{6}\left(k_{1, x}+2 k_{2, x}+2 k_{3, x}+k_{4, x}\right) \\
& y_{j+1}=y_{j}+\frac{1}{6}\left(k_{1, y}+2 k_{2, y}+2 k_{3, y}+k_{4, y}\right) \\
& z_{j+1}=z_{j}+\frac{1}{6}\left(k_{1, z}+2 k_{2, z}+2 k_{3, z}+k_{4, z}\right) \\
& u_{j+1}=u_{j}+\frac{1}{6}\left(k_{1, u}+2 k_{2, u}+2 k_{3, u}+k_{4, u}\right)
\end{aligned}
$$

Selanjutnya dengan program MATLAB diselidiki hubungan antara biaya per investasi $(b)$ dengan kestabilan titik tetap sehingga diperoleh

G. Analisis kestabilan titik tetap ketika biaya per investasi $b<0.7068$

Simulasi menggunakan parameter seperti pada [6]. Misalkan Misalkan $a=0.9, c=1.5, d=0.2, k=0.05$ dan $m=0.005$ agar system bersifat stabil maka nilai $b<$ 0.7068. Ambil nilai $b=0.4$ dengan kondisi awal seperti pada [6] $\left(x_{0}, y_{0}, z_{0}, u_{0}\right)=(0,1,-0.5,0)$, diperoleh

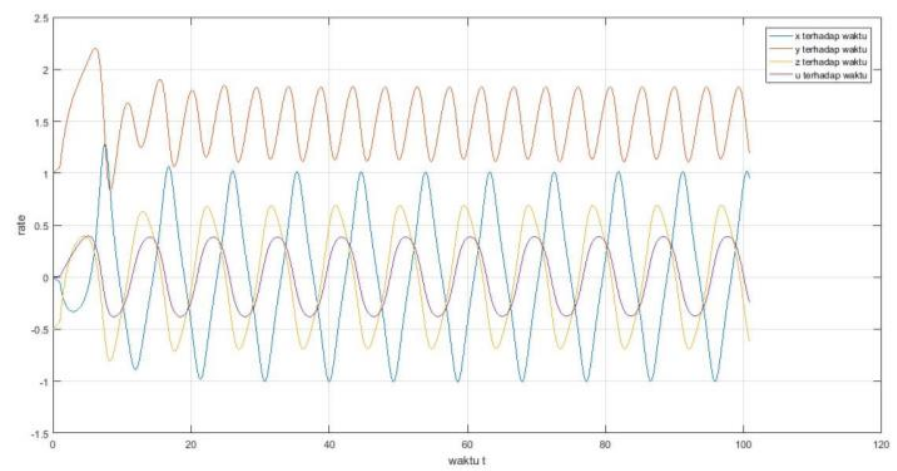

Gambar 8. Grafik Kestabilan (x,y,z,u) terhadap fungsi $\mathrm{t}($ waktu) pada saat $b=$ 0.4

\section{1) Laju Perubahan Suku Bunga $(x)$}

Berdasarkan Gambar 8, dapat diketahui bahwa penyelesaian untuk suku bunga dengan nilai awal sebesar 0 berosilasi seiring bertambahnya waktu jauh dari titik 0 .

2) Laju Perubahan Tingkat Permintaan Investasi $(y)$

Berdasarkan Gambar 8, dapat diketahui bahwa penyelesaian untuk tingkat permintaan investasi dengan nilai awal 1 berosilasi seiring bertambahnya waktu jauh dari titik 1. 


\section{3) Laju Perubahan Indeks Harga Instrumen Keuangan (\$) Laju Perubahan Control Input (u)}

Berdasarkan Gambar 8, dapat diketahui bahwa penyelesaian untuk indeks harga instumen keuangan dengan nilai awal sebesar -0.5 berosilasi seiring bertambahnya waktu jauh dari titik -0.5 .

4) Laju Perubahan Control Input

Berdasarkan Gambar 8, dapat diketahui bahwa penyelesaian untuk control input dengan nilai awal 0 berosilasi seiring bertambahnya waktu jauh dari titik 0 .

Intepretasi dari hasil analisis dan hasil simulasi Pada Gambar 8 menunjukkan bahwa fenomena yang terjadi pada sistem keuangan real memenuhi kondisi dimana suku bunga akan naik turun tidak terkendali seiring bertambahya waktu. Hal tersebut berdampak pada naik turunnya harga instrumen keuangan sehingga indeks harga intrumen juga ikut naik turun. Tingkat permintaan investasi naik turun karena para pelaku akan mengikuti kondisi yang ada dan control input juga tidak terlaksana secara maksimal akibatnya pemerintah juga kesulitan untuk mengontrol. Akibatnya, total kegiatan produksi tidak mencukupi untuk total konsumsi di masyarakat. pada kondisi ini, sistem keuangan tidak stabil.

\section{H. Analisis kestabilan titik tetap ketika biaya per investasi} $b>0.7068$

Simulasi menggunakan parameter seperti pada [7]. Misalkan Misalkan $a=0.9, c=1.5, d=0.2, k=0.05$ dan $m=0.005$ agar system bersifat stabil maka nilai $b>$ 0.7068. Ambil nilai $b=0.9$ dengan kondisi awal seperti pada [7] $\left(x_{0}, y_{0}, z_{0}, u_{0}\right)=(0,1,-0.5,0)$, diperoleh

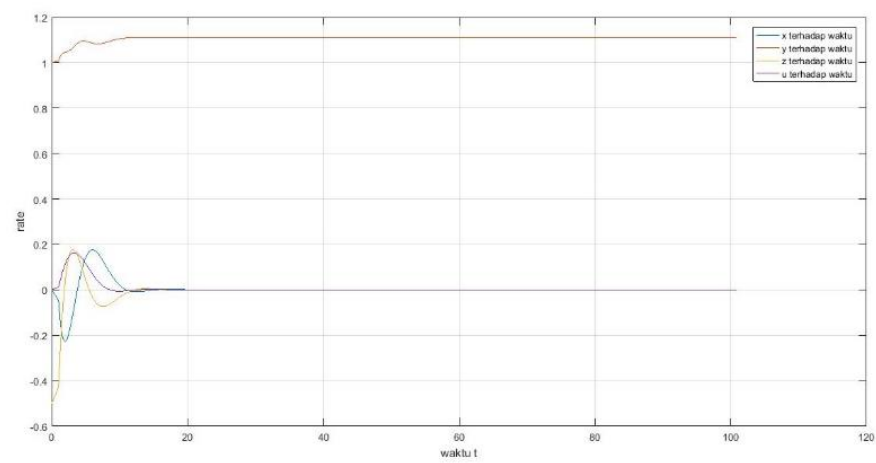

Gambar 9. Grafik Kestabilan (x,y,z,u) terhadap fungsi t(waktu) pada saat $b=$ 0.9

\section{1) Laju Perubahan Suku Bunga ( $x$ )}

Berdasarkan Gambar 9, dapat diketahui bahwa penyelesaian untuk suku bunga dengan nilai awal sebesar 0 beriosilasi bergerak naik kemudian bergerak didekat titik 0 dan konstan di titik 0 seiring bertambahnya waktu.

2) Laju Perubahan Tingkat Permintaan Investasi (y)

Berdasarkan Gambar 9, dapat diketahui bahwa penyelesaian untuk tingkat permintaan investasi dengan nilai awal 1 bergerak naik mendekati titik 1,11 kemudian konstan seiring bertambahnya waktu.

3) Laju Perubahan Indeks Harga Instrumen Keuangan

Berdasarkan Gambar 9, dapat diketahui bahwa penyelesaian untuk indeks harga instumen keuangan dengan nilai awal sebesar -0.5 bergerak naik dan setelah itu berosilasi mendekati titik 0 kemudian konstan di titik 0 seiring bertambahnya waktu.
Berdasarkan Gambar 9, dapat diketahui bahwa penyelesaian untuk control input dengan nilai awal 0 bergerak naik turun dan berosilasi mendekati titik 0 , kemudian konstan di 0 seiring bertambahnya waktu.

Interpretasi dari hasil analisis dan hasil simulasi menunjukkan bahwa ketika fenomena yang terjadi pada sistem keuangan memenuhi kondisi ini, maka sistem keuangan akan stabil dengan penambahan kontrol input yaitu dari pemerintah memberikan kebijakan yang mana kebijakan tersebut berpengaruh langsung terhadap tinggi rendahnya indeks harga instrumen keuangan, dengan mengontrol biaya per investasi maka suku bunga menjadi turun namun akan naik kembali dan konstan kembali di angka yang seharusnya dengan seiring bertambahnya waktu, tingkat permintaan investasi dan indeks harga instrumen meningkat dengan seiring berjalannya waktu menjadi konstan di angka yang seharusnya. Kondisi ini memberikan gambaran dimana sistem keuangan berjalan dengan baik dan perekonomian berjalan lancar karena adanya kebijakan pemerintah yang mana mengontrol biaya per investasi agar tinggi rendahnya suku bunga, tingkat permintaan investasi dan juga indeks harga instrumen keuangan yang sesuai pada kondisi ini menyebabkan total kegiatan produksi tetap mencukupi untuk total konsumsi di masyarakat.

\section{KESIMPULAN}

Berdasarkan keseluruhan hasil analisis yang telah dilakukan, dapat disimpulkan bahwa

1. Pada model sistem keuangan dengan empat variable diperoleh 3 titik tetap

- Ketika $y_{0}=\frac{1}{b}$ maka diperoleh titik tetap $E_{0}\left(0, \frac{1}{b}, 0,0\right)$

- dan ketika $y_{0}=\frac{-(k+a c k+a m)}{d-c k-m}$ dengan syarat $d-$ $c k-m \neq 0$ dan dapat kita misalkan $\Gamma_{1}=d-c k-$ $m$ dan $\Gamma_{2}=-(k+a c k+a m)$ dengan $0<\Gamma_{1}<$ $b \Gamma_{2}$ maka didapat titik tetap $E_{1,2}\left( \pm x_{0}, y_{0}, \bar{\mp} z_{0}, \bar{\mp} u_{0}\right)$ dimana

$$
\begin{gathered}
x_{0}=\frac{\Gamma_{1}-b \Gamma_{2}}{\Gamma_{1}} \\
y_{0}=\frac{\Gamma_{2}}{\Gamma_{1}} \\
z_{0}=(a d+k) \frac{\Gamma_{1}-b \Gamma_{2}}{\Gamma_{1}^{\frac{3}{2}}} \\
u_{0}=(d+a c d-m) \frac{\Gamma_{1}-b \Gamma_{2}}{\Gamma_{1}^{\frac{3}{2}}}
\end{gathered}
$$

- $E_{*}$ adalah titik tetap yang didalamnya ada titik tetap $E_{0}$ dan $E_{1,2}$

2. Kestabilan pada titik tetap $E_{*}\left(x_{*}, y_{*}, z_{*}, u_{*}\right)$ berlaku saat $h_{1}, h_{2}, h_{3}, h_{4}>0, h_{1} h_{2}-h_{3}>0$ dan $h_{1} h_{2} h_{3}-h_{3}^{2}-$ $h_{1}^{2} h_{4}>0$. Nilai-nilai tersebut diperoleh menggunakan kriteria Routh-Hurwitz. Bifurkasi Hopf juga dapat terjadi pada titik tetap ini jika $h_{0}>0, h_{1}, h_{2}, h_{3}, h_{4}>0, h_{1} h_{2}-$ $h_{3}>0 \quad$ dan $\quad h_{1} h_{2} h_{3}-h_{3}^{2}-h_{1}^{2} h_{4}=0 \quad$ berlaku sedemikian hingga

$$
\frac{d}{d b}\left(h_{1} h_{2} h_{3}-h_{3}^{2}-h_{1}^{2} h_{4}\right) \neq 0
$$


3. Bifurkasi Hopf terjadi pada titik tetap $E_{0}$ dimana ketika biaya per investasi $b=b_{0}=0.7068$ sistem masuk kedalam bifurkasi Hopf mengelilingi titik tetap positif.

4. Dengan metode Numerik Runge-Kutta orde-4 menggunakan software MATLAB, diperoleh penyelesaian numerik dari sistem keuangan memberikan hasil yang sama dengan hasil analisis untuk kestabilan titik tetap.

\section{DAFTAR PUSTAKA}

[1] IMF, Compilation Guide on Financial Soundness Indicators. Washington D.C, 2004.

[2] C. Y. Ma, J., "Study for The Global Complicated Character of A
Kind of Non-Linear Finance System. I," Appl. Math. Mech. Vol. 22, vol. 11, pp. 1240-1251, 2001.

[3] L. X,-D, Zhang., X, -D, Liu., Y, Zheng., and C, "Chaotic Dynamic Behavior Analysis and Control For A Financial Risk System," Chinese Physic B, vol. 22, no. 3, 2013.

[4] U. J, A, Holyst., K, "Chaos Control In Economical Model by TimeDelayed Feddback Method," Phys. A Stat. Mech. Its Appl., vol 287, no. 3-4, pp. 587-589, 2000.

[5] Subiono, "Sistem Linear dan Kontrol Optimal," ITS, 2013.

[6] W. Liu, "Criterion of Hopf Bifurcation without Using Eigen Values," 1994.

[7] A. G, Kai., W, Zhang., Z, C, Wei., J, F, Wang., and A, "Hopf Bifurcation, Positively Invariant Set, and Phisical Realization of a New Four-Dimensional Hyperchaotic Financial System," Math. Probl. Eng., 2017. 